\title{
INFLUENCE OF LONG TERM EXPOSURE IN AIR ON MICROSTRUCTURE, SURFACE STABILITY AND MECHANICAL PROPERTIES OF UDIMET 720LI
}

\author{
Dietmar Helm and Olaf Roder \\ DaimlerChrysler Aerospace, MTU Motoren- und Turbinen-Union München GmbH \\ Dachauer Strasse 665 \\ 80995 Munich, Germany
}

\begin{abstract}
Alloy Udimet $720 \mathrm{LI}$ was designed for high temperature application of aircraft-engine disks up to about $730^{\circ} \mathrm{C}$. Operating at such high temperatures for long times raises the question of thermodynamical stability of the alloy (bulk stability) and surface integrity. Subject of the present paper was to investigate the influence of long time exposure up to 1000 hours at high temperatures up to $845^{\circ} \mathrm{C}$ in air on microstructure and phase stability as well as on surface integrity. It could be shown by appropriate microscopy (LM, SEM, TEM) that coarsening of the $\gamma^{\prime}$-phase occurred with increasing time of exposure at temperatures of $760^{\circ} \mathrm{C}$ and $845^{\circ} \mathrm{C}$. Additional formation of topological closed packed (TCP) phases $(\sigma)$ could be observed. It was found that this lack of stability exhibited an impact on mechanical properties such as tensile strength, creep resistance, and low cycle fatigue strength, especially when a dwell time was superimposed. Furthermore, the reaction of the alloy in the near-surface area of the specimen exposed to air at high temperatures with superimposed stresses was investigated by light microscopy (LM) and SEM. A quantitative analysis by EDX investigation in a SEM of the thus formed surface oxide layer and the subsurface area with a depletion of alloying elements was performed.
\end{abstract}




\section{INTRODUCTION}

UDIMET* 720LI (U720LI) is a high strength corrosion *UDIMET is a trademark of Special Metals Corporation resistant nickel-based superalloy, precipitation strengthened by $\gamma^{\prime}, \mathrm{Ni}_{3}(\mathrm{Al}, \mathrm{Ti})$, and solution strengthened by $\mathrm{Mo}, \mathrm{W}, \mathrm{Cr}$ and $\mathrm{Co}$, being particularly used in aeroengines for highly stressed rotating components, such as compressor and turbine disks. U720LI (low inclusion chemistry) is a derivative from UDIMET 720 (U720, conventional chemistry), an alloy originally designed for optimum oxidation and sulfidization resistance for turbine blades operating in the harsh environment of land-based turbine engines. The chemistry of U720LI is optimized for improved phase stability and reduced carbide and boride stringers for cast and wrought processed material. Table I shows the nominal compositions of U720 and U720LI.

Table I Nominal Composition of U720 and U720LI

\begin{tabular}{|l|c|c|c|c|c|c|c|c|c|}
\hline Alloy & Cr & Co & Mo & W & Ti & Al & C & B & Zr \\
\hline U720 & 18 & 14.7 & 3.0 & 1.25 & 5.0 & 2.5 & 0.035 & 0.033 & 0.03 \\
\hline U720LI & 16 & 14.7 & 3.0 & 1.25 & 5.0 & 2.5 & 0.010 & 0.015 & 0.03 \\
\hline
\end{tabular}

U720LI as well as U720 have received increased interest due to their good balance of mechanical properties and economic potential. It has been reported that cast and wrought U720LI is less costly than comparable competitive $\mathrm{P} / \mathrm{M}$ alloys [1]. The original chemistry of U720 has a problem with phase stability, especially in the fine grained subsolvus heat treated condition. The high chromium content of the conventional U720 chemistry makes it prone to sigma phase formation. Figure 1 (adopted from [2]) shows the effect of composition on the precipitation of sigma phase in subsolvus heat treated material for U720 by comparing sigma phase formation "C"-curves of U720 with U720LI.

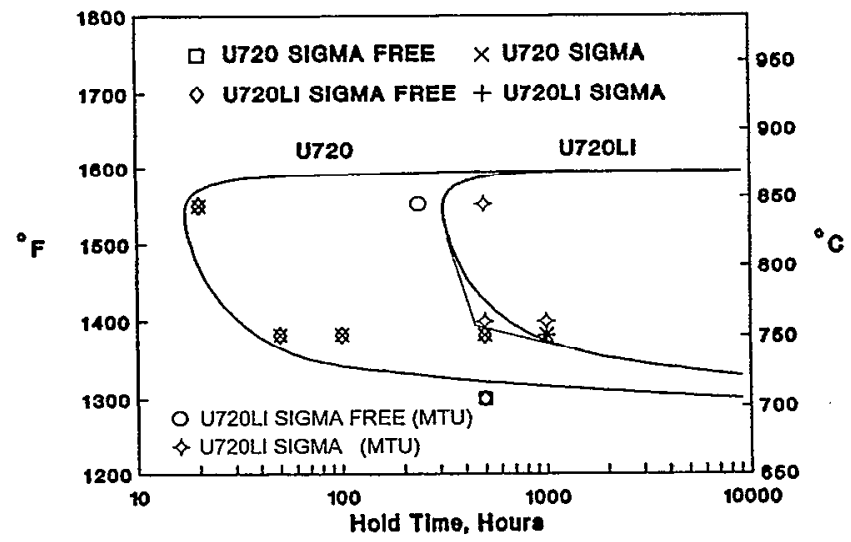

Figure 1: Effect of composition on the precipitation of $\sigma-$ phase in subsolvus heat treated U720 [2]
Mechanical property and microstructure changes with inservice thermal exposures have shown that sigma phase formation in U720 is very deleterious [2]. Recent studies of the stability of U720LI have shown that this material is susceptible to sigma phase formation, though to a much lower degree as compared to U720 [3].

The objective of this study was to investigate the influence of long time exposure up to 1000 hours at high temperatures up to $845^{\circ} \mathrm{C}$ in air on microstructure and phase stability as well as on surface integrity for U720LI.

\section{EXPERIMENTAL PROCEDURE}

For the purpose of the present work specimen blanks were taken from a regular cast and wrought U720LI disk, which was heat treated as listed below:

- $\quad 4 \mathrm{~h} 1100^{\circ} \mathrm{C} / \mathrm{Oil}$ Quench

- $24 \mathrm{~h} 650^{\circ} \mathrm{C} / \mathrm{AC}+16 \mathrm{~h} 760^{\circ} \mathrm{C} / \mathrm{AC}$

This condition was used to determine the baseline microstructure and mechanical properties to which all other conditions were compared. Table II shows the various conditions being produced by different exposure heat treatments of the baseline condition. All exposure heat treatments were performcd in air in a laboratory furnace followed by furnace cooling.

Table II Performed Exposure Heat Treatments

\begin{tabular}{|l|c|l|}
\hline Condition & Heat Treatment & Investigation \\
\hline $760-\mathrm{S}$ & $500 \mathrm{~h} 760^{\circ} \mathrm{C}$ & $\mathrm{LM}$, SEM, TEM \\
\hline $760-\mathrm{L}$ & $1000 \mathrm{~h} 760^{\circ} \mathrm{C}$ & $\mathrm{LM}$, SEM, TEM, MT \\
\hline $845-\mathrm{S}$ & $120 \mathrm{~h} 845^{\circ} \mathrm{C}$ & $\mathrm{LM}$ \\
\hline $845-\mathrm{M}$ & $240 \mathrm{~h} 845^{\circ} \mathrm{C}$ & $\mathrm{LM}, \mathrm{SEM}$ \\
\hline $845-\mathrm{L}$ & $500 \mathrm{~h} 845^{\circ} \mathrm{C}$ & $\mathrm{LM}$, SEM \\
\hline
\end{tabular}

Characterization of the microstructural changes as a function of thermal exposure heat treatment were performed by optical microscopy (LM), scanning electron microscopy including energy disperse $\mathrm{X}$-ray measurements (SEM) and transmission electron microscopy. As the thermal exposure of $1000 \mathrm{~h}$ at $760^{\circ} \mathrm{C}$ seems to be a reasonable upper bound limit for microstructural changes under a practical point of view (maximum accumulation of time at this temperature during the whole engine life), mechanical testing was performed on the baseline condition and on condition 760-L. Mechanical testing (MT) included ambient and hot tensile testing up to $750^{\circ} \mathrm{C}$, creep testing under two test conditions, $625^{\circ} \mathrm{C}$ at $730 \mathrm{MPa}$ and $670^{\circ} \mathrm{C}$ at $650 \mathrm{MPa}$, and load controlled fatigue testing at $700^{\circ} \mathrm{C}\left(\mathrm{k}_{\mathrm{t}}=2.1\right)$ without dwell time and with a dwell time of 1 minute. All mechanical tests were performed in laboratory air. Most specimens were machined after thermal exposure to study the influence of bulk stability 
(designation for example 760-L). Additionally, some specimens were heat treated with finished surface to determine surface integrity effects superimposed to bulk effects on mechanical properties (designation for example 760-L Surface).

\section{RESULTS AND DISCUSSION}

The effect of heat treatment on the stability of U720LI is illustrated in Figures 2 to 4 by comparing optical, SEM and TEM micrographs showing the microstructural changes of conditions 760-S, 760-L, 845-M and 845-L.

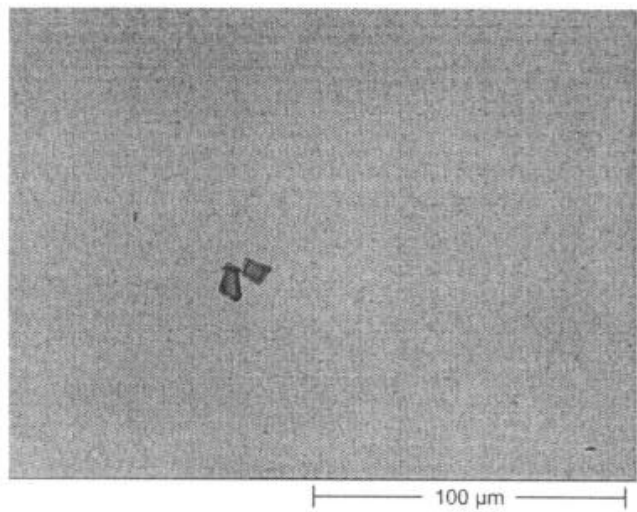

Figure 2a: Baseline Condition, no $\sigma$-phase

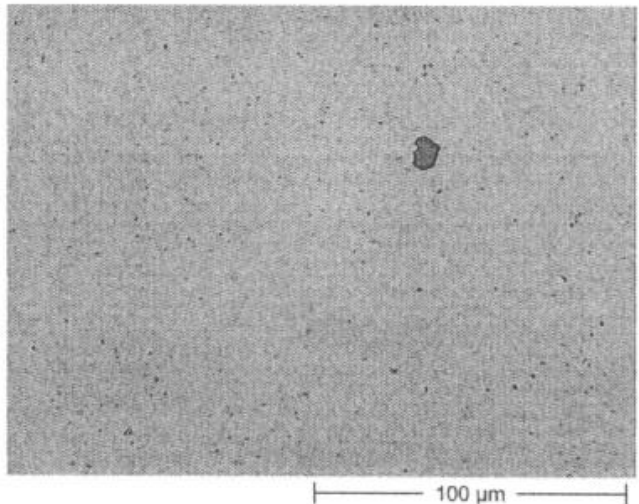

Figure 2b: Condition 760-S, small amount of $\sigma$-phase

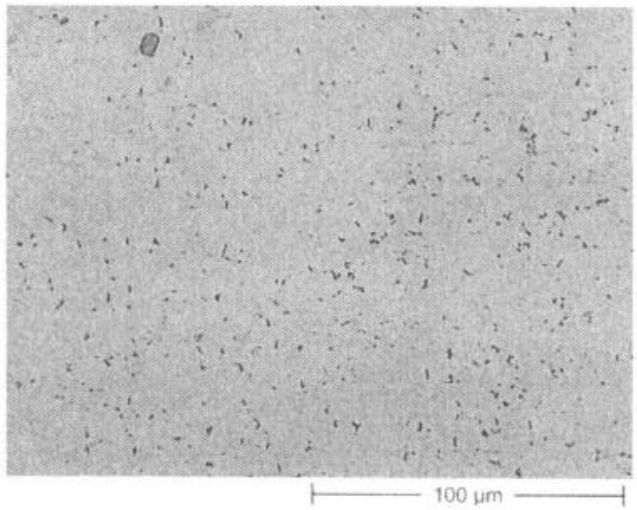

Figure 2c: Condition 760-L, $\sigma$-phase present

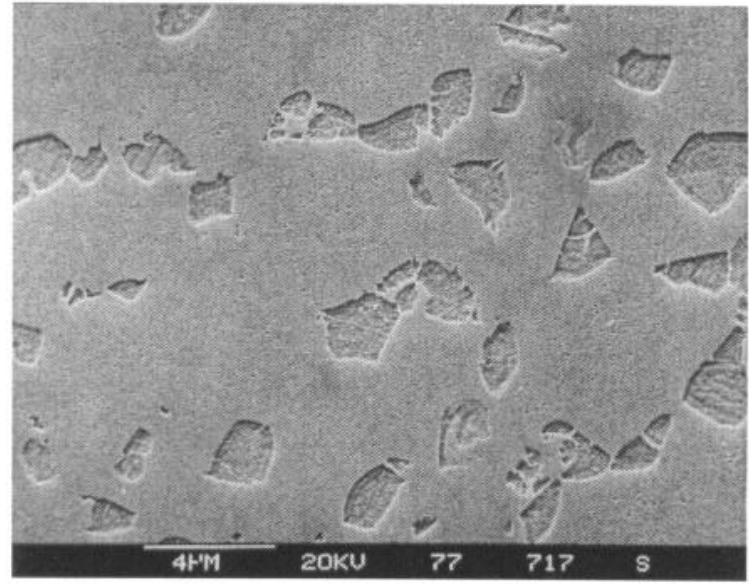

Figure 3a: Baseline Condition, SEM

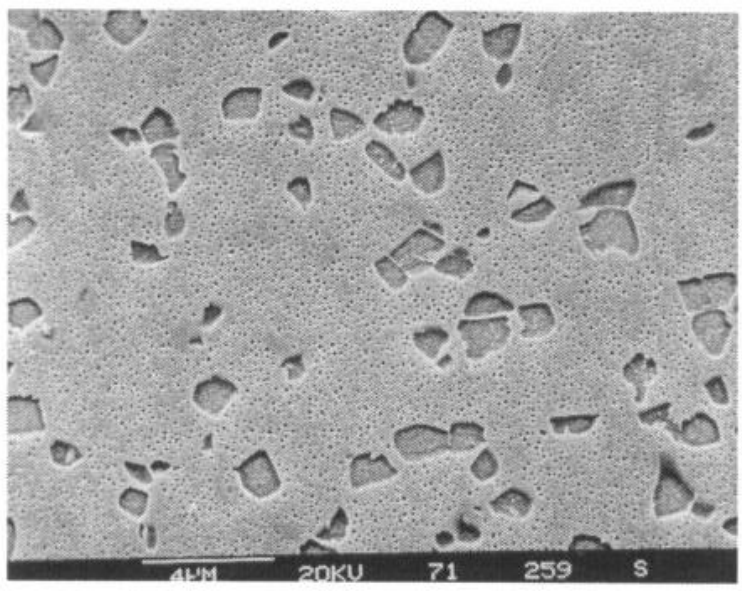

Figure 3b: Condition 845-M, SEM

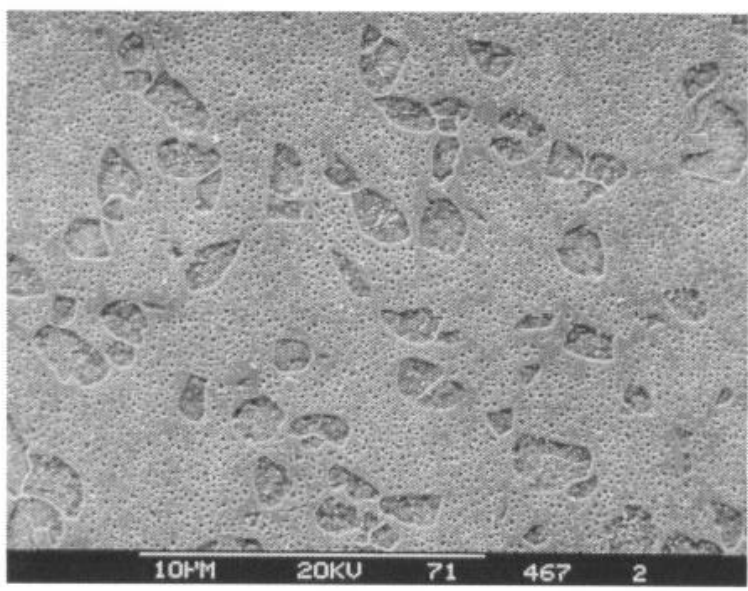

Figure 3c: Condition 845-L, SEM 


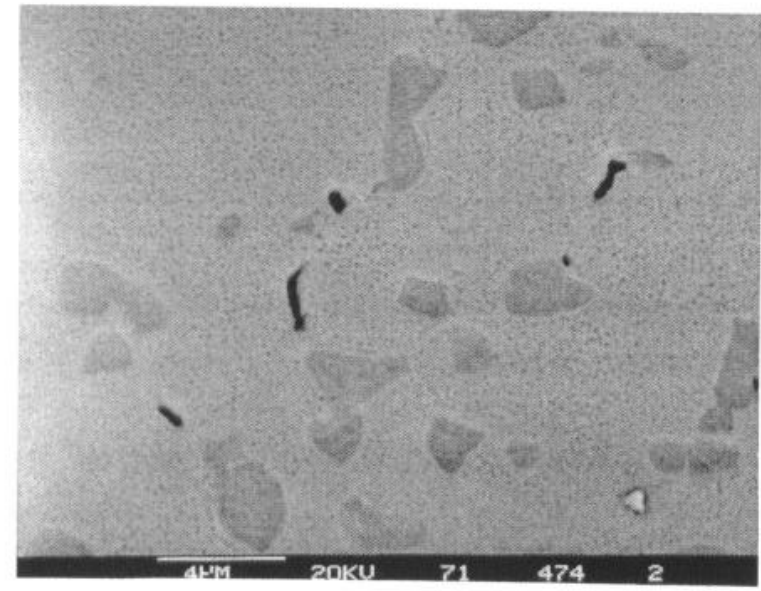

Figure 3d: Condition 845-L, $\sigma$-phase, SEM

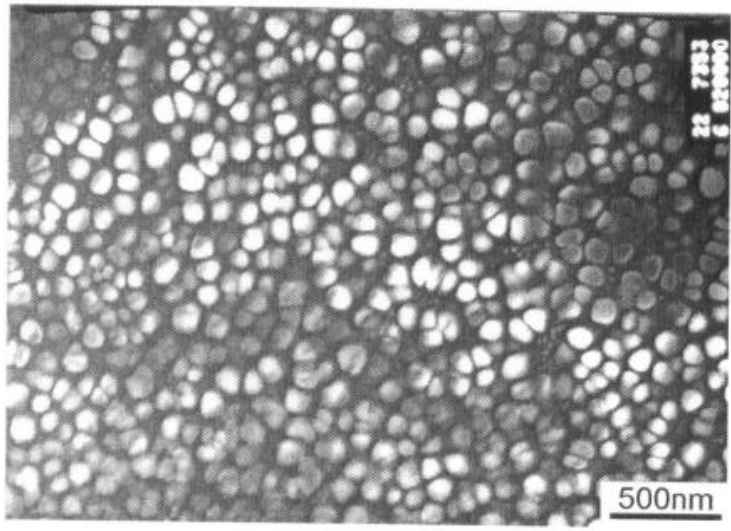

Figure 4a: Baseline condition, size of secondary $\gamma^{\prime}$, TEM

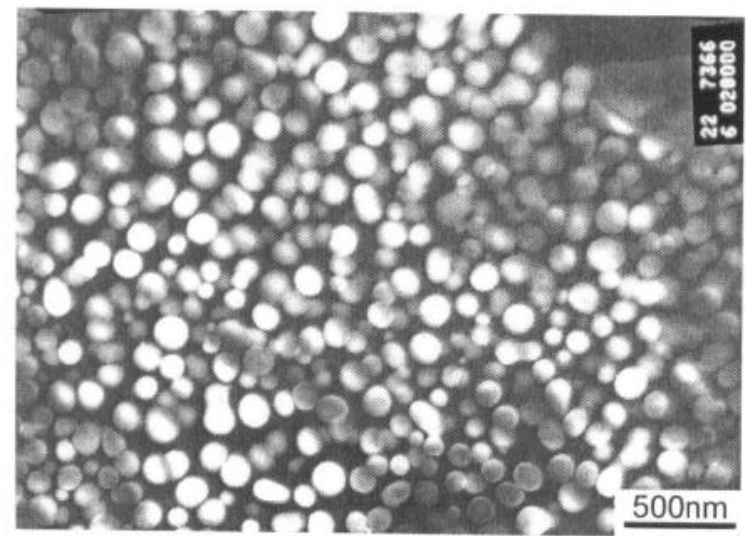

Figure 4b: Condition 760-L, size of secondary $\gamma$ ', TEM

The exposure of U720LI to high temperatures lead on one hand to a coarsening of the secondary $\gamma$, the size of these particles grows from about $70 \mathrm{~nm}$ in the base-condition (Fig. 3a, Fig. 4a ) to sizes of about $150 \mathrm{~nm}$ in condition 760-L (Fig. 4b) and 845-L (Fig. 3c). Table III lists the size of the secondary $\gamma$ ' particles for all six conditions. On the other hand the high temperature exposure lead to the formation of TCP-phases in conditions 760-S, 760-L and 845-L (Fig. 2b, c, Fig. 3d). The phases in conditions 760-S, 760-L and 845-L supposed to be $\sigma$-phase were analyzed using quantitative energy disperse X-ray (EDX) measurements. These measurements showed an increase in $\mathrm{Cr}$, Mo and $\mathrm{Co}$ and a depletion of $\mathrm{Ni}$ for these phases compared to the analysis of the surrounding matrix thus indicating that these phases are $\sigma$-phase, the measured composition being about $\left(\mathrm{Cr}_{0.5}, \mathrm{Mo}_{0.1}\right),\left(\mathrm{Ni}_{0.2}, \mathrm{Co}_{0.2}\right)$ and matching the suggested composition in [4]. The information on the presence of $\sigma$-phase is incorporated into figure 1 confirming the existing data from [2] mainly. Our data suggest that the slope of the C-curve for U720LI at lower temperatures is a little smaller and the upwards turn starts at lower temperatures (see updated Fig. 1).

Table III Size of secondary $\gamma^{\prime}$

\begin{tabular}{|l|c|}
\hline Condition & $\begin{array}{c}\text { Secondary } \gamma^{\prime} \text { size } \\
{[\mathbf{n m}]}\end{array}$ \\
\hline Base & $70-100$ \\
\hline $760-\mathrm{S}$ & $\sim 125$ \\
\hline $760-\mathrm{L}$ & $\sim 150$ \\
\hline $845-\mathrm{S}$ & not investigated \\
\hline $845-\mathrm{M}$ & $\sim 110$ \\
\hline $845-\mathrm{L}$ & $\sim 150$ \\
\hline
\end{tabular}

Furthermore some investigations were performed to study the influence of long time high temperature exposure on the surface integrity of U720LI. Figure 5 shows as an example a SEM micrograph of condition $845-\mathrm{L}$ being exposed to $845^{\circ} \mathrm{C}$ for $500 \mathrm{~h}$ without machining the surface afterwards.

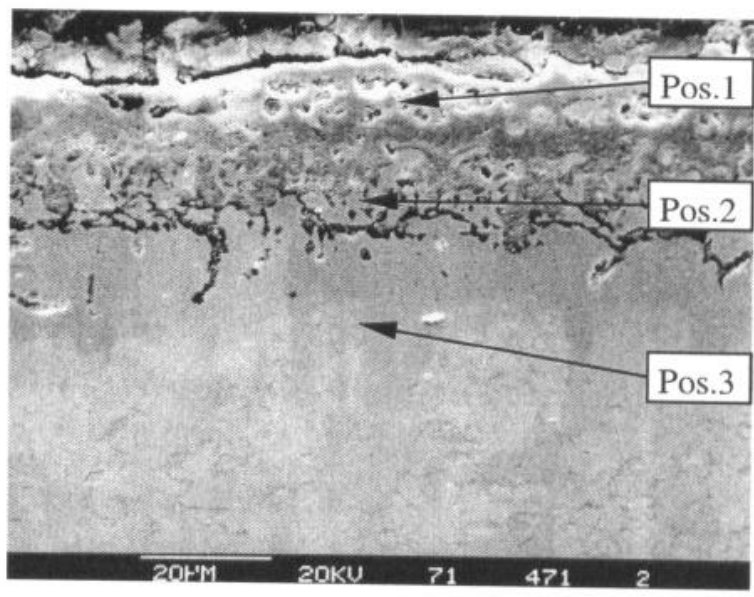

Figure 5: Condition 845-L, near surface microstructural changes

Typical microstructural changes near and at the surface after long time high temperature exposure can be described 
as a relatively dense zone on the surface (Fig. 5, Pos.1), followed by a porous zone (Fig. 5, Pos. 2) just below the surface and a zone below these two zones which shows a depletion of the $\gamma^{\prime}$ particles (Fig. 5, Pos.3). EDX-analysis of the three zones are listed in table IV.

Table IV EDX-analysis in wt.-\% of near surface area in condition $845-\mathrm{L}$ with surface exposed to high temperature

Position (Pos) see Figure 5

\begin{tabular}{|l|l|l|l|l|l|l|l|}
\hline $\mathrm{Pos}$ & $\mathrm{O}_{2}$ & $\mathrm{Al}$ & $\mathrm{Ti}$ & $\mathrm{Cr}$ & $\mathrm{Co}$ & $\mathrm{Mo}$ & $\mathrm{Ni}$ \\
\hline 1 & 41 & 3,8 & 11,2 & 28,9 & 3,4 & 0,9 & 10,3 \\
\hline 2 & 11,5 & 4,0 & 3,1 & 13,0 & 15,2 & 4,3 & 55,2 \\
\hline 3 & 8,8 & 1,6 & 4,9 & 13,7 & 14,1 & 3,3 & 53,1 \\
\hline & & & & & & & \\
\hline Nom & & 2,5 & 5,0 & 16 & 14,7 & 3,0 & 57,5 \\
\hline
\end{tabular}

Mechanical properties were determined for the baseline condition which did not show any presence of $\sigma$-phase at all and for condition 760- $\mathrm{L}$ with $\sigma$-phase in the microstructure. Figure 6 shows the tensile properties as a function of test temperature for the above mentioned conditions.

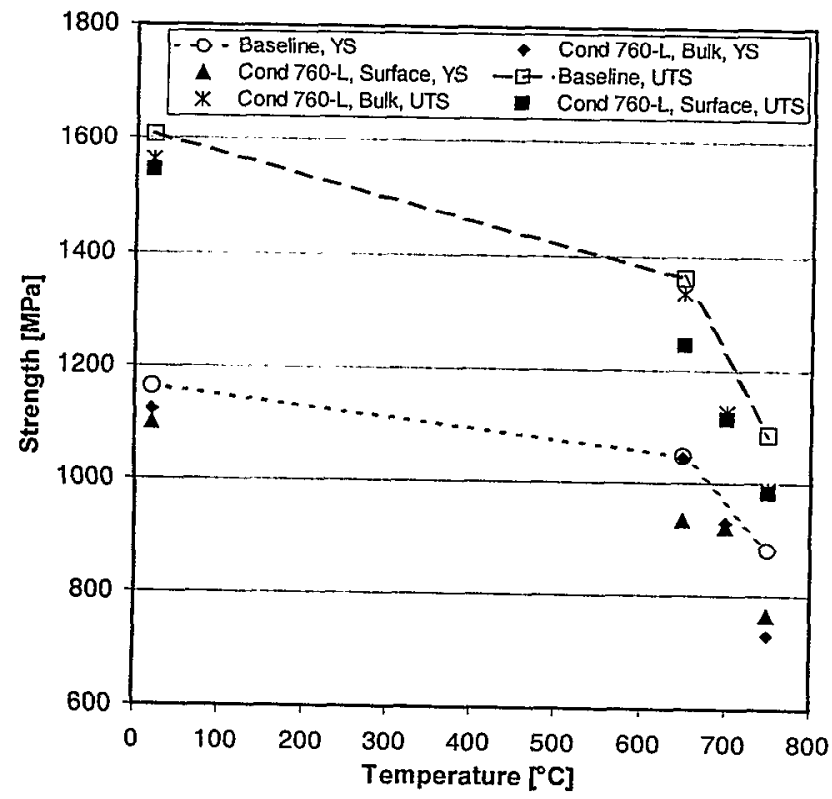

Figure 6a: 0.2\% Yield Strength (YS) and Ultimate Tensile Strength (UTS) as a function of test temperature for baseline condition (NO $\sigma$-phase) and condition 760-L ( $\sigma$-phase present)

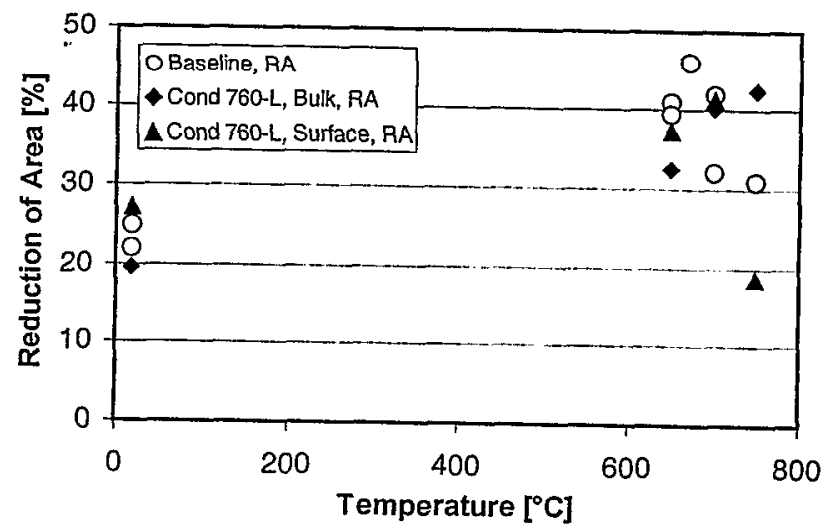

Figure 6b: Reduction of Area (RA) as a function of test temperature for baseline condition (NO $\sigma$ phase) and condition 760-L ( $\sigma$-phase present)

The tensile data presented above (Figures $6 \mathrm{a}$ and $6 \mathrm{~b}$ ) illustrate several important features of property changes due to coarsening of secondary $\gamma^{\prime}$ and $\sigma$-phase precipitation.

The strength values of condition 760-L are lower over the whole temperature range as compared to the baseline condition. The drop in strength is higher for higher temperatures. No differences were observed between the two variations of condition $760-\mathrm{L}$ (760-L and $760-\mathrm{L}$ Surface).

The strength of $\gamma^{\prime}$ hardened nickel-based superalloys arises from a combination of hardening mechanisms. On one hand there are alloying additions in solid solution to provide strength, creep resistance and/or resistance to surface degradation and on the other hand nickel-base alloys contain elements that form small coherent particles of an intermetallic compound of the type $\mathrm{Ni}_{3}(\mathrm{Al}, \mathrm{Ti})$ after an appropriate thermo-mechanical processing or heat treatment, contributing to strength, creep and fatigue resistance [5]. On this basis the decrease in strength of condition $760-\mathrm{L}$ as compared to the baseline condition can be explained:

1. The coarsening of the secondary $\gamma^{\prime}$ particles leads to a change of the interface of these particles and by that to a change of the dislocation - particle interaction. In the baseline condition the secondary $\gamma^{\prime}$ particles are coherent and moving dislocations will pass the particles by a cutting mechanism. With increasing time of high temperature exposure (condition 760-L) the secondary $\gamma^{\prime}$ particles grow and become semicoherent or in-coherent, forcing moving dislocations to pass by an Orowan-looping mechanism. This would be a reasonable explanation why at a constant volume fraction of $\gamma^{\prime}$ an increasing particle size (secondary $\gamma^{\prime}$ ) and corresponding increasing particle spacing leads to a decrease in strength. 
2. Additionally the depletion of the $\gamma$-matrix from $\mathrm{Cr}, \mathrm{Co}$, and Mo due to the precipitation of $\sigma$-phase will reduce solid solution strengthening by these elements and therefore lead to a further decrease in strength. The decrease in strength due to depletion of solid solution strengthening elements is smaller compared to the mechanism described under 1 ., due to the small volume fraction of $\sigma$-phase precipitated in condition 760-L. As Co is a stronger solid solution strengthening element at high temperatures, the depletion of Co might be responsible for the bigger decrease in strength at higher temperatures.

Values of reduction of area do not show any differences between the baseline condition and both variations of condition $760-\mathrm{L}$. Above temperatures of about $650^{\circ}$ the data scatter more in comparison to lower temperatures and show a decreasing tendency after reaching a maximum at about $670^{\circ} \mathrm{C}$ (Fig. 6b). This behavior is probably due to an increasing contribution of grain boundary sliding to the fracture process at temperatures above $670^{\circ} \mathrm{C}$ in U720LI. Condition 760-L does not show a different behavior compared to the baseline condition, indicating that the volume fraction of $\sigma$-phase is too small to influence the fracture behavior in short term mechanical tests. Furthermore, similar tensile test results of both variations of condition 760-L (without and with superimposed surface effects) indicates, that the surface and near-surface changes of the microstructure (Fig. 5) due to long time high temperature exposure do not lead to an embrittlement of the material.

Table IV compares the results of the creep testing for condition 760-L with typical results of the alloy.

Table IV Results of creep testing condition 760-L

\begin{tabular}{|l|c|c|}
\hline & $\begin{array}{c}\mathbf{t}_{\mathbf{0 , 2} \%} \\
{[\mathbf{h}]}\end{array}$ & $\begin{array}{c}\varepsilon_{\mathrm{pl}, 100 \mathrm{~h}} \\
{[\%]}\end{array}$ \\
\hline \multicolumn{3}{|c|}{ Test Conditions: $625^{\circ} \mathrm{C}, 730 \mathrm{MPa}$} \\
\hline Typical & 230 & 0.1 \\
\hline $760-\mathrm{L}$, Bulk & 32 & 0.4 \\
\hline \multicolumn{3}{|c|}{ Test Conditions: $670^{\circ} \mathrm{C}, 650 \mathrm{MPa}$} \\
\hline Typical & 50 & 0.3 \\
\hline $760-\mathrm{L}$, Bulk & $5-8$ & $1.14-2.15$ \\
\hline
\end{tabular}

The creep results show a drastic drop in creep resistance for condition $760-\mathrm{L}$ compared to the baseline condition, expressed by an increase in time to $0.2 \%$ plastic strain and/or plastic strain after $100 \mathrm{~h}$, respectively.

Creep in nickel-based superalloys is very dependent of a number of microstructural parameters. Thus, several of the above described changes in the microstructure are to a certain extent responsible for the deterioration of the creep resistance of condition 760-L compared to the baseline condition. Besides the decrease of the creep resistance due to the overall decrease of high temperature strength as a result of the coarsening of the secondary $\gamma^{\prime}$ particles and the depletion of solid solution strengthening elements, it is well known [6] that the appearance of $\sigma$-phase noticeably impairs the creep strength. The loss in properties associated with the formation of phases such as $\sigma$ usually is either the result of the depletion of alloying elements contributing to solid solution strengthening, or is due to cracking in the new phase or at the new phase-matrix interface.

Figure 7 presents the results of the load controlled fatigue tests of notched specimens $\left(k_{t}=2.1\right)$ on the baseline condition and condition $760-\mathrm{L}$, performed at $700^{\circ} \mathrm{C}$ without a dwell time and with a dwell time of 1 minute.

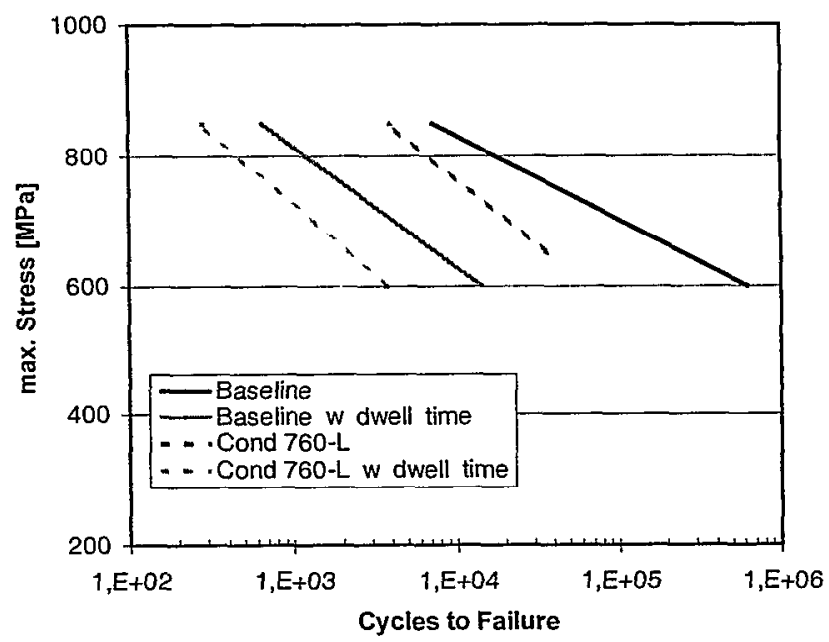

Figure 7: Results of fatigue testing, $700^{\circ} \mathrm{C}, \mathrm{R}=0.1$, $k_{t}=2.1$

For the baseline condition the tests with a dwell time of 1 minute per cycle show a decrease in life (cycles to failure) by a factor of about 10 for high maximum stresses and of about 15 for lower stresses as compared to the tests without a dwell time. Condition 760-L shows a further drop of life by a factor of 2-3 as compared to the baseline condition for both test conditions (without a dwell time as well as with a dwell time).

At $700^{\circ} \mathrm{C}$ fatigue life becomes dependent not only on the number of cycles but also on the time per cycle. The accumulated time especially at high loads contributes significantly to the total life. At high maximum stresses the total number of cycles to failure is relatively small and the difference in total life between samples tested without a dwell time and those tested with a dwell time is mainly due 
to the accumulated time at maximum stress and the resultant creep damage. At lower maximum stresses the number of cycles to failure becomes bigger and thus the time at maximum stress increases accumulating additional creep damage. This may explain the increasing difference in life time with increasing total life for tests performed with a dwell time and those performed without a dwell time for the baseline condition.

The difference in total life for condition 760-L when compared to the baseline condition can be explained by the difference of the creep resistances. As described above the creep resistance of condition 760-L is much lower than the creep resistance of the baseline condition and therefore exhibits a lower total fatigue life at $700^{\circ} \mathrm{C}$ with accumulated creep damage contributing significantly to the total life.

\section{CONCLUSIONS}

Long time high temperature exposure of the nickel-based superalloy UDIMET 720LI in a subsolvus heat treated fine grained condition for aero-engine disk application lead to the changes in the microstructure listed below and as a result of this to significant changes of important mechanical properties:

- Long time exposure at temperatures up to $845^{\circ} \mathrm{C}$ and times up to $1000 \mathrm{~h}$ increases the size of the secondary $\gamma$ ' particles and under certain combinations of time and temperature $\sigma$-phase is precipitated.

- $\sigma$-phase formation in the microstructure is observed in U720LI material exposed for $500 \mathrm{~h}$ to $845^{\circ} \mathrm{C}, 500 \mathrm{~h}$ to $760^{\circ} \mathrm{C}$ and $1000 \mathrm{~h}$ to $760^{\circ} \mathrm{C}$.

- From a practical point of view (maximum accumulation of time at this temperature during the whole engine lifc) thermal cxposure at $760^{\circ} \mathrm{C}$ for $1000 \mathrm{~h}$ seems to be a reasonable upper bound limit for estimating the maximum possible deterioration of mechanical properties.

- Tensile strength from room temperature to $750^{\circ} \mathrm{C}$ (YS as well as UTS) was reduced by 5 to $10 \%$ when $\sigma$ phase was present.

- Creep resistance was reduced significantly by a factor of about 5 .

- Load controlled fatigue tests performed at $700^{\circ} \mathrm{C}$ without a dwell time as well as with a dwell time of 1 minute showed a decrease in total life (cycles to failure) by a factor of 2 to 3 as compared to their baseline counterparts.

These results show that long time high temperature exposure of U720LI leads to a significant deterioration of the important mechanical properties. Furthermore these results indicate that the practical maximum temperature for long time usage should be below $730^{\circ} \mathrm{C}$.

\section{ACKNOWLEDGEMENTS}

This work was supported by the Bundesministerium für Bildung und Forschung (BMBF).

Prof. G. Lütjering of the Technical University of HamburgHarburg is kindly acknowledged for performing TEM work.

\section{REFERENCES}

1. G. Kappler et. al., "Conventionally Procecessed High Performance Disc Material for Advanced Aeroengine Design", $4^{\text {th }}$ European Propulsion Forum 1993, Bath, UK, pp. 9.1-9.9

2. P. W. Keefe, S. O. Mancuso, G. E. Maurer, "Effects of Heat Treatment and Chemistry on the Long-Term Phase Stability of a High Strength Nickel-Based Superalloy", in Superalloys 1992, Eds. S.D. Antolovich et. al., The Minerals, Metals \& Materials Society, 1992, pp. 487-496

3. Y. S. Na, et. al. "Quantification of Sigma Precipitation Kinetics in Udimet 720LI", Proc. of the $4^{\text {th }}$ Intl. Charles Parsons Turbine Conference, Newcastle, UK, November 4-6, 1997, pp. 685-697

4. R. C. Reed, M. P. Jackson, and Y. S. Na, "Characterization and Modeling of the Precipitation of the Sigma Phase in UDIMET 720 and UDIMET 720LI", Metallurgical and Materials Transactions A, Volume 30A, March 1999, pp. 521-533

5. C. T. Sims, N.S. Stoloff, and W. C. Hagel, "Superalloys II", Chapter 3, John Wiley \& Sons, New York 1997, pp.61-96

6. C. T. Sims, N.S. Stoloff, and W. C. Hagel, "Superalloys II", Chapter 9, John Wiley \& Sons, New York 1997, pp.241-262 